\title{
Penanggulangan Kasus Gizi Kurang dengan Intervensi Penyuluhan dan Pengukuran Antropometri di Desa Rugemuk Kecamatan Pantai Labu
}

\author{
Nadya Ulfa Tanjung ${ }^{1}$, Fiyola Yoana $\mathrm{P}^{2}$, Rahayu $\mathrm{M}^{2}$, Sahrul Amin ${ }^{2}$, Tri D.A.Zega ${ }^{2}$ \\ ${ }^{1}$ FKM UIN Sumatera Utara, ${ }^{2}$ Institut Kesehatan Sumatera Utara
}

Corresponding author: JI IAIN N0 1 Medan, Sumatera Utara. Email : nadyaulfa.tanjung@gmail.com

\section{Riwayat Artikel}

Diterima: 25 November 2021

Disetujui: 12 Desember 2021

Dipublikasi: 26 Desember 2021

\section{Keywords}

Malnutrition, children, counseling, cooking demonstrations, measuring nutritional status

\begin{abstract}
Medan is part of North Sumatra Province. The prevalence of undernutrition and malnutrition in Medan in 2013 was $19.3 \%$, consisting of $4.2 \%$ malnutrition and $15.1 \%$ malnutrition. The prevalence rate is close to the national figure, which is $19.6 \%$. Based on the 2015 MDGs target, the prevalence of malnutrition and children under five is $15.5 \%$, this prevalence rate is included in the high category. The method used in this community service is counseling, demonstration and measurement of nutritional status. held on 6, 12 and 24 February 2020 in Rugemuk Village. The result of the service, namely counseling was carried out 3 times. It was conducted once at the Puskesmas Rugemuk Village, 2 times at the Posyandu Hamlet 1 and Hamlet III in Rugemuk Village, Pantai Labu District. From the results of the intervention and observations made, there are several children in Rugemuk Village whose nutritional status is less. Counseling is not only carried out at the Posyandu, but also students conduct counseling at the Rugemuk Village Health Center, Dusun II. Participants seemed satisfied with the holding of nutrition counseling with the theme according to the counseling target. Participants seemed enthusiastic when participating in nutrition counseling activities for each target group. The conclusion in this service is that intervention activities carried out to solve problems are counseling to the community as well as data collection and measurement of height and weight in children. All activities are carried out well and smoothly, outreach to the community as well as data collection and measurement of children's height and weight.
\end{abstract}

\section{PENDAHULUAN}

Munculnya masalah gizi pada anak dipengaruhi oleh banyak faktor yang saling terkait. Secara langsung dipengaruhi oleh beberapa hal, yaitu anak tidak cukup mendapat makanan bergizi seimbang pada usia balita, anak tidak mendapatkan asuhan gizi yang memadai dan 
anak menderita penyakit infeksi. Kemiskinan juga merupakan salah satu penyebab munculnya kasus gizi buruk terkait ketersediaan dan konsumsi pangan keluarga (Depkes RI, 2010).

Identifikasi stunting dilakukan dengan membandingkan tinggi anak dengan standar tinggi anak pada populasi normal sesuai dengan usia dan jenis kelamin yang sama. Anak digolongkan stunting jika tingginya berada dibawah -2 SD dari standar WHO. South East Asean Nutrition Survey (SEANUTS) pada tahun 2010-2011 melaporkan Indonesia sebagai negara dengan jumlah balita stunting terbesar diatas Malaysia, Thailand dan Vietnam (Trihono, 2015). Prevalensi stunting secara nasional di Indonesia mengalami peningkatan dari 35,6\% tahun 2010 menjadi 37,2\% tahun 2013. Prevalensi stunting pada balita di Indonesia terus meningkat, dari 18,0\% tahun 2007 (Riskesdas, 2007), 17,1\% di tahun 2010 (Riskesdas, 2010) dan naik menjadi 19,2\% di tahun 2013 (Riskesdas, 2013). Data Pemantauan Status Gizi (PSG) selama tiga tahun terakhir mencatat bahwa prevalensi stunting mengalami peningkatan dari tahun 2016 yaitu 27,5\% menjadi 29,6\% pada tahun 2017 (Nina,dkk.2019).

Stunting dianggap menjadi masalah kesehatan masyarakat kategori kronis bila prevalensinya sebesar $\geq 20 \%$. Menurut data Riskesdas ada 14 propinsi di Indonesia yang stunting tergolong masalah kesehatan masyarakat berat dan 15 propinsi tergolong serius dan salah satunya adalah Propinsi Sumatera Utara. (Nina,dkk.2019)

Secara umum di Indonesia masalah gizi buruk masih merupakan salah satu masalah utama yang di hadapi sampai sekarang. Berdasarkan Riset Kesehatan Dasar (RISKESDAS) Tahun 2010 dari 26,7 juta balita tercatat bahwa indonesia masih terdapat 4,9\% balita gizi buruk, $13,0 \%$ balita dengan status gizi kurang 7,3\% balita (Depkes RI, 2011). Prevalensi stunting di Sumatera Utara tahun 2017 (Data PSG) adalah 28,4\%. Artinya Sumatera Utara masih dalam kondisi bermasalah kesehatan masyarakat. Prevalensi stunting tertinggi di Sumatera Utara tersebar di 4 Kabupaten/Kota yaitu Langkat, Padang Lawas, Nias Utara dan Gunung Sitoli. Langkat adalah kabupaten dengan prevalensi stunting tertinggi yaitu 54.961 jiwa pada tahun 2013 atau sekitar 55,48\% dibandingkan dengan Padang Lawas yang prevalensi stuntingnya 54,86\%, Nias Utara 54,83\% dan Gunung Sitoli 52,32\% (Tim Nasional Percepatan Kemiskinan, 2018). (Nina,dkk.2019).

Promosi kesehatan menurut World Health Organization (WHO) adalah merevitalisasi pendidikan dengan istilah promosi kesehatan, kalau pendidikan kesehatan diartikan sebagai upaya perubahan perilaku, maka promosi kesehatan tidak hanya untuk perubahan perilaku, tetapi juga perubahan lingkungan yang memfasilitasi perubahan perilaku tersebut, disamping itu promosi kesehatan lebih menekankan pada peningkatan kemampuan hidup sehat, bukan sekedar berperilaku sehat. (Kholid A, 2013).

Provinsi Sumatera Utara yang terdiri atas 33 kabupaten/kota memiliki angka prevalensi balita gizi buruk dan kurang pada tahun 2013 sebesar 22,4\% yang terdiri dari 8,3\% gizi buruk dan 14,1\% gizi kurang. Angka ini lebih tinggi 2,8\% dengan angka prevalensi gizi berat dan kurang secara nasional, yaitu 19,6\%. Prevalensi gizi kurang dan gizi buruk sebesar $22,4 \%$ di Sumatera Utara masih termasuk dalam kategori tinggi. Dari 33 kabupaten/kota di Sumatera Utara, 17 provinsi memiliki prevalensi gizi berat dan kurang di atas angka prevalensi provinsi, yaitu berkisar antara 22,6\% di kabupaten Serdang Bedagai sampai $41,4 \%$ di kabupaten Padang Lawas. Angka prevalensi gizi buruk dan kurang tertinggi terdapat pada 3 (tiga) kabupaten, yaitu Kabupaten Padang Lawas sebesar 41,4\%, Nias Utara sebesar 40,7\% dan Nias Barat sebesar 37,5\%. Sedangkan berdasarkan sasaran MDG's 2015 prevalensi gizi buruk dan kurang pada balita sebesar 15,5\%. (Dinkes Sumut, 2015).

Kota Medan merupakan salah satu bagian wilayah Provinsi Sumatera Utara. Prevalensi gizi kurang dan gizi buruk di Kota Medan tahun 2013 sebesar 19,3\% yang terdiri dari 4,2\% gizi buruk dan 15,1\% gizi kurang. Angka prevalensi ini mendekati angka nasional, yaitu sebesar 19,6\%. Sedangkan berdasarkan sasaran MDG's 2015 prevalensi gizi buruk dan kurang 
pada balita sebesar $15,5 \%$, angka prevalensi ini termasuk dalam kategori tinggi (Dinkes Sumut, 2015).

\section{METODE}

Posyandu dilaksanakan tanggal 6, 12, dan 24 Februari 2020 di Desa Rugemuk. Cara pelaksanaannya hanya menggunakan Dacin dan KMS. Masyarakat yang mengikuti posyandu adalah ibu-ibu yang mempunyai bayi dan balita. Peserta posyandu yang datang mendaftarkan balitanya, langsung ditimbang berat badan dan mengukur tinggi badannya dan setelah itu dicatat berat badan dan tinggi badannya. Selanjutnya ibu-ibu mendapatkan Pemberian Makanan Tambahan berupa bubur kacang hijau dan telur rebus yang diberikan oleh kader setiap dusun. Setelah penyuluhan selesai, peserta posyandu pulang ke rumah masing-masing.

Metode yang digunakan dapam pengabdian masyarakat ini adalah penyuluhan kesehatan yang berisi 12 Pesan Umum Gizi Seimbang (PUGS), tips hidup sehat melalui nutrisi dan imunisasi yang menggunakan metode ceramah dengan media penyuluhan berupa poster dan dilaksanakan di Dusun I-IV Desa Rugemuk. Dalam melakukan pendataan dan pengukuran status gizi anak-anak di desa rugemuk perlu dilakukan beberapa langkah yaitu :

1. Persiapan

Untuk melakukan pendataan dan pengukuran di desa dibutuhkan persiapan untuk kelancaran pelaksanaan di desa dengan menghubungi kepala desa Rugemuk untuk meminta izin melakukan kegiatan pendataan dan pengukuran tinggi badan dan berat badan anak-anak di desa rugemuk, menentukan tempatnya, menyiapkan kuesioner yang dalam pelaksanaan pendataan di desa serta mempersiapkan peralatan yang di butuhkan.

2. Pelaksanaan

Kegiatan pendataan dan pengukuran berat tinggi badan dan berat badan anak-anak dilaksanakan didesa rugemuk dengan berkunjung kerumah warga serta melakukan wawancara lansung dengan masyarakat.

3. Kesimpulan pelaksanaan kegiatan pendataan dan pengukuran tinggi badan dan berat badan

Kesimpulan dari pendataan dan pengukuran tinggi badan dan berat badan anak-anak didesa rugemuk, masyarakat sangat antusias menerima kami untuk melakukan pendataan dan pengukuran kepada anak-anak mereka.

\section{HASIL DAN PEMBAHASAN}

Berdasarkan pertimbangan diatas maka dipilih intervensi masalah yang akan dilaksanakan yaitu: Penyuluhan tentang 12 tips hidup sehat dengan menggunakan metode ceramah dengan alat bantu poster serta pendataan dan pengukuran tinggi badan dan berat badan.

Tabel 1. Matriks Rencana Intervensi

\begin{tabular}{llllll}
\hline No & $\begin{array}{c}\text { Pilihan } \\
\text { Intervensi }\end{array}$ & Efektivitas & \multicolumn{1}{c}{ Dana } & $\begin{array}{c}\text { Dukungan } \\
\text { Masyarakat }\end{array}$ & Pengorganisasian \\
\hline 1. & $\begin{array}{l}\text { Penyuluhan 12 } \\
\text { PUGS, tips }\end{array}$ & Sangat & Tidak & Masyarakat & Mudah untuk \\
& berpengaru & membutuhk & bersedia & dilakukan karena \\
dengan nutrisi & berhubunga & an dana & melakukan dan & sasaran \\
& & & megitu & mendukung & langsungkepadama \\
\hline
\end{tabular}




\begin{tabular}{|c|c|c|c|c|c|}
\hline & dan imunisasi & $\begin{array}{l}\text { n langsung } \\
\text { dengan } \\
\text { masyarakat. }\end{array}$ & besar. & $\begin{array}{l}\text { berjalannya } \\
\text { kegiatan. }\end{array}$ & $\begin{array}{l}\text { syarakat yang ada } \\
\text { di Desa Rugemuk. }\end{array}$ \\
\hline 2. & $\begin{array}{l}\text { Pendataan } \\
\text { dan } \\
\text { pengukuran } \\
\text { tinggi badan } \\
\text { dan berat } \\
\text { badan }\end{array}$ & $\begin{array}{l}\text { Masyarakat } \\
\text { dapat } \\
\text { langsung } \\
\text { megikuti } \\
\text { pelaksanaa } \\
\mathrm{n} \\
\text { pendataan } \\
\text { dan } \\
\text { pengukuran } \\
\text { status gizi. }\end{array}$ & $\begin{array}{l}\text { Tidak } \\
\text { membutuhk } \\
\text { an dana. }\end{array}$ & $\begin{array}{l}\text { Masyarakat } \\
\text { sangat } \\
\text { mendukung } \\
\text { pelaksanaanya. }\end{array}$ & $\begin{array}{l}\text { Mudah dilakukan } \\
\text { karena sasaran } \\
\text { langsung ada } \\
\text { dirumah. }\end{array}$ \\
\hline
\end{tabular}

\section{Penyuluhan Gizi}

Kamampuan keberanian dan keterampilan berbicara lulusan pendidikan tenaga kesehatan, khususnya tenaga gizi, sangat diperlukan. Mereka diprogramkan siap pakai sebagai penyuluh dilapangan berhadapan langsung dengan masyarakat. Penyuluhan dilakukan di Desa Rugemuk Dusun II, III, dan IV, yang didampingi oleh setiap kader masing-masing dusun. Penyuluhan tidak hanya dilakukan di Posyandu.

Tabel 2. Matriks Kerja Lanjutan Intervensi Akar Masalah di Desa Rugemuk Kecamatan Pantai Labu Tahun 2020

\begin{tabular}{cllll}
\hline No & Pilihan Intervensi & $\begin{array}{l}\text { Peningkatan } \\
\text { Pengetahuan }\end{array}$ & Dampak & Kelangsungan \\
\hline 1 & $\begin{array}{l}\text { Penyuluhan 12 PUGS, } \\
\text { tips hidup sehat } \\
\text { dengan nutrisi dan } \\
\text { imunisasi }\end{array}$ & Besar & $\begin{array}{l}\text { Dapat } \\
\text { berkelanjutan }\end{array}$ \\
2 & $\begin{array}{l}\text { Pendataan dan } \\
\text { pengukuran dinggi } \\
\text { badan dan berat } \\
\text { badan }\end{array}$ & Besar & Dapat \\
berkelanjutan
\end{tabular}

\section{Evaluasi Kegiatan Penyuluhan Gizi}

1. Evaluasi Struktur

Sasaran untuk penyuluhan gizi yaitu dari berbagai organisasi masyarakat, mulai dari Anak Sekolah, Remaja Mesjid, dan Posyandu. Pelaksanaan penyuluahan gizi dilakukan di Kelurahan Rugemuk yang dilaksanakan sesuai dengan planning of action yang telah direncanakan. Media yang digunakan saat penyuluhan adalah bahan penyuluhan yang sudah disipakan dan di fotokopi yang di fasilitasi oleh mahasiswa.

2. Evaluasi Proses

Pelaksanaan kegiatan dilakukan berdasarkan planning of action. Peserta penyuluhan hadir mengikuti kegiatan dari awal sampai akhir.

3. Evaluasi Hasil

Peserta tampak puas dengan diadakannya penyuluhan gizi dengan tema sesuai sasaran penyuluhan. Peserta tampak antusias saat mengkuti kegiatan penyuluhan gizi untuk tiaptiap kelompok sasaran. 


\section{Materi Penyuluhan}

1. 12 Pedoman Umum gizi Seimbang (PUGS) dam tips hidup sehat dengan nutrisi dan imunisasi

2. Gizi Kurang Pada Anak dan Balita

3. Imunisasi

\section{Frekuensi Penyuluhan}

Penyuluhan dilakukan sebanyak 3 kali. 1 kali di lakukan di Puskesmas Desa Rugemuk, 2 kali dilakukan di Posyandu Dusun 1 dan Dusun III di Desa Rugemuk Kecamatan Pantai Labu.

\section{Hambatan Saat Penyuluhan}

Hambatan yang ditemui pada saat pelaksanaan kegiatan adalah sasaran tidak fokus mendengarkan penyuluhan dan pengukuran antropometri karena waktu yang dipilih saat itu sempit, bertepatan dengan jam pulang nelayan dari laut yang notabenenya adalah suami para peserta, sehingga mereka tidak sabar menunggu kegiatan selesai dan berkeinginan untuk pulang secepatnya. Hanya beberapa orang saja yang terlihat fokus dan mau mendengarkan materi yang disampaikan, padahal saat kegiatan terlaksana tim didampingi oleh Kepala Seksi Gizi dari Puskesmas dan kader kesehatan setempat.

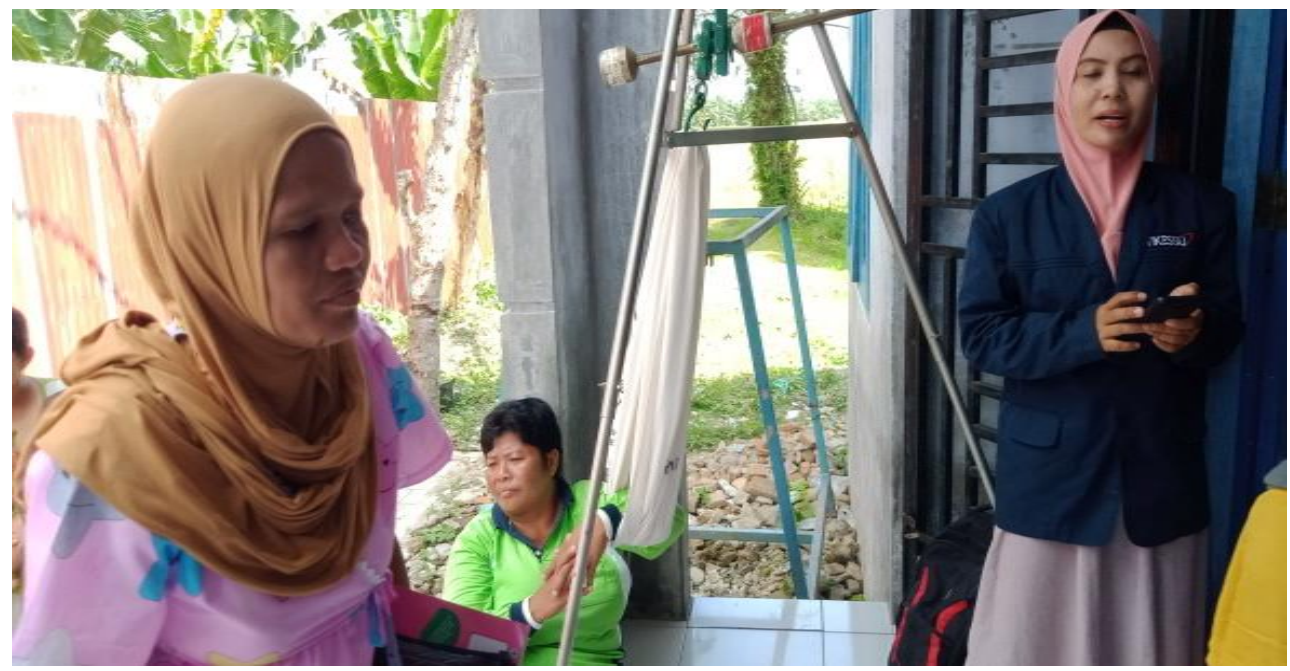

Gambar 1. Dokumentasi Penyuluhan

Hasil Status Gizi Kurang dan Gizi Buruk Pada Anak

Dari hasil intervensi dan observasi yang dilakukan terdapat beberapa anak di Desa Rugemuk yang status gizi nya kurang. Hasil pengolahan data yang telah dilakukan untuk menentukan status gizi anak adalah dengan cara menggunakan rumus berdasarkan BB/U. Berikut data gizi kurang yang berhasil dihimpun : 
Table 3. Hasil Perhitungan Status Gizi Anak

\begin{tabular}{cccccc}
\hline $\begin{array}{c}\text { No } \\
\text { Responden }\end{array}$ & $\begin{array}{c}\text { Jenis } \\
\text { Kelamin }\end{array}$ & Umur & BB & TB & $\begin{array}{c}\text { Satatus Gizi } \\
\text { BB/U }\end{array}$ \\
\hline 1 & Pr & 22 bulan & $7 \mathrm{~kg}$ & $73,3 \mathrm{~cm}$ & Gizi buruk \\
2 & $\mathrm{Lk}$ & 30 bulan & $12,3 \mathrm{~kg}$ & $95,2 \mathrm{~cm}$ & Gizi kurang \\
3 & $\mathrm{Lk}$ & 7 tahun & $19,1 \mathrm{~kg}$ & $118 \mathrm{~cm}$ & Gizi kurang \\
4 & $\mathrm{Lk}$ & 12 tahun & $20,2 \mathrm{~kg}$ & $130,5 \mathrm{~cm}$ & Gizi buruk \\
5 & $\mathrm{Lk}$ & 27 bulan & $10,8 \mathrm{~kg}$ & $75 \mathrm{~cm}$ & Gizi kurang \\
6 & $\mathrm{Lk}$ & 4 bulan & $6,2 \mathrm{~kg}$ & $13,3 \mathrm{~cm}$ & Gizi lebih \\
7 & $\mathrm{Pr}$ & 32 bulan & $9,8 \mathrm{~kg}$ & $82 \mathrm{~cm}$ & Gizi kurang \\
8 & $\mathrm{Pr}$ & 11 bulan & $3,4 \mathrm{~kg}$ & $68 \mathrm{~cm}$ & Gizi kurang \\
9 & $\mathrm{Pr}$ & 24 bulan & $9,8 \mathrm{~kg}$ & $79,5 \mathrm{~cm}$ & Gizi kurang \\
10 & $\mathrm{Lk}$ & 36 bulan & $12,6 \mathrm{~kg}$ & $95 \mathrm{~cm}$ & Gizi kurang \\
11 & $\mathrm{Pr}$ & 48 bulan & $13,7 \mathrm{~kg}$ & $95 \mathrm{~cm}$ & Gizi kurang \\
12 & $\mathrm{Pr}$ & 24 bulan & $7,4 \mathrm{~kg}$ & $73,5 \mathrm{~cm}$ & Gizi kurang \\
13 & $\mathrm{Lk}$ & 24 bulan & $10 \mathrm{~kg}$ & $93 \mathrm{~cm}$ & Gizi kurang \\
14 & $\mathrm{Pr}$ & 24 bulan & $7,8 \mathrm{~kg}$ & $80 \mathrm{~cm}$ & Gizi kurang \\
15 & $\mathrm{Lk}$ & 15 bulan & $6,2 \mathrm{~kg}$ & $65,5 \mathrm{~cm}$ & Gizi kurang \\
16 & $\mathrm{Pr}$ & 27 bulan & $8,3 \mathrm{~kg}$ & $74 \mathrm{~cm}$ & Gizi kurang \\
17 & $\operatorname{Pr}$ & 40 bulan & $12,1 \mathrm{~kg}$ & $83 \mathrm{~cm}$ & Gizi kurang \\
\hline
\end{tabular}

Berdasarkan tabel diatas memperlihatkan bahwa anak yang mengalami gizi kurang di Desa Rugemuk sebanyak 14 orang, dan yang mengalami gizi buruk terdapat 2 orang, 1 orang yang status gizinya lebih atau obesitas.
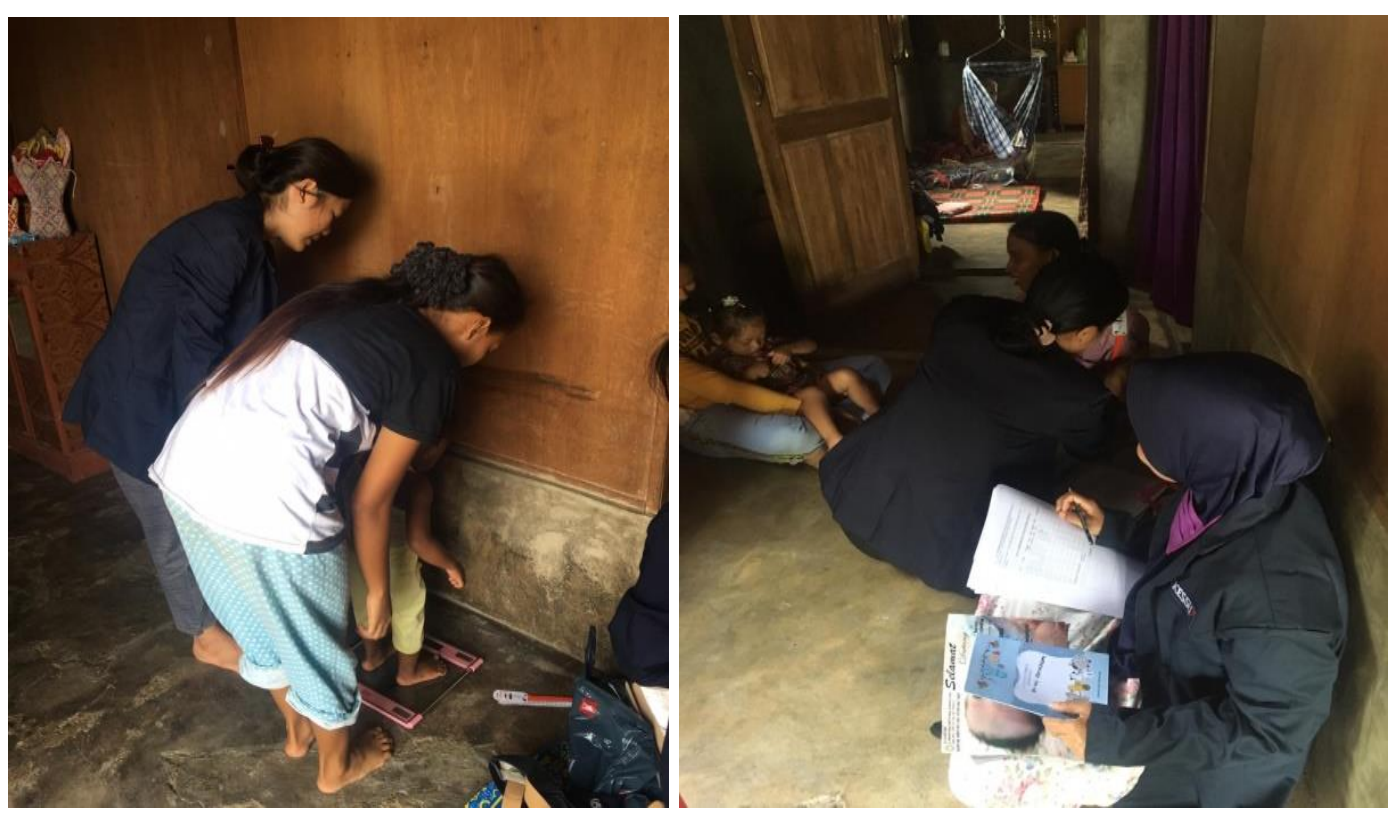

Gambar 3. Dokumentasi Pengukuran Status Gizi

\section{KESIMPULAN}

Nadya Ulfa Tanjung, dkk, Penanggulangan Kasus Gizi Kurang Dengan Intervensi Penyuluhan Dan Pengukuran Antropometri di Desa Rugemuk Kec. Pantai Labu 
Masalah kesehatan adalah masalah tentang gizi kurang pada anak-anak. Kegiatan intervensi yang dilakukan untuk menyelesaikan masalah adalah penyuluhan pada masyarakat serta pendataan dan pengukuran tinggi badan dan berat badan pada anak. Semua kegiatan berjalan dengan baik dan lancar, penyuluhan kepada masyarakat serta pendataan dan pengukuran tinggi badan dan berat badan pada anak-anak.

\section{DAFTAR REFERENSI}

Adisasmito, Agung. (2007). Pengantar Pangan Dan Gizi. Jakarta : Penebar Swadaya

Ahmed, T., Hossain, M., \& Sanin, K. I. (2012). Global burden of maternal and child undernutrition and micronutrient deficiencies. Annals of Nutrition and Metabolism, 61(Suppl. 1), 8-17.

Alamsyah,dkk.2017. Beberapa faktor resiko gizi kurang dan gizi buruk pada balita 12-59 bulan. Jurnal epidemiologi kesehatan komunitas 2 (1), 54-62.

Almatsier, (2004). Prinsip Dasar Ilmu Gizi. Jakarta: PT Gramedia Pustaka Umum.

Anwar, H. M. (2008). Peranan gizi dan pola asuh dalam meningkatkan kualitas tumbuh kembang anak. www.whandi.net.

Arisman. 2004. Gizi Dalam Daur Kehidupan. Jakarta: EGC.

Bachtiar, H. (2009). Faktor Determinan Kejadian Gondok di Daerah Pantai

Jawa Timur. Jurnal Kesehatan Masyarakat, 3(2), 62-67.

Berihun, S., Kassa, G. M., \& Teshome, M. 2017. Factors associated with underweight among lactating women in Womberma woreda, Northwest Ethiopia; a crosssectional study. BMC Nutrition, 3(1), 46.

Chapman, D. J., \& Nommsen-Rivers, L. (2012). Impact of maternal nutritional status on human milk quality and infant outcomes: an update on key nutrients. Advances in Nutrition, 3(3), 351-352.

Depkes RI. 1995. Pedoman Anemia Gizi. Jakarta: Departemen Kesehatan RI.

Depkes RI. 2006. Modul Desa Siaga. Jakarta : Depkes RI

Depkes RI. (2004). Keluarga Sadar Gizi (KADARZI): Mewujudkan keluarga cerdas dan mandiri. Jakarta: Depkes.

Depkes. (2010). Petunjuk Teknis Standar Pelayanan Minimal (SPM). Penyelenggaraan Perbaikan Gizi Masyarakat. Jakarta ; 2010.

Depkes. (2011). Klasifikasi Status Gizi Anak Bawah Lima Tahun (BALITA). Jakarta: Direktorat Jendral Bina Kesehatan Masyarakat.

Devi, Nirmala, 2012, Gizi Anak Sekolah, PT Kompas Media Nusantara, Jakarta.

Dirjen Gizi. 2015. Kesehatan Dalam Kerangka SDGS. Jakarta: Kemenkes RI

Fatmah. 2007. Gizi dan Kesehatan Masyarakat. Jakarta: Rajagrafindo Persada.

Fajrina, N. (2016). Hubungan Faktor Ibu Dengan Kejadian Stunting Pada Balita Di Puskesmas Piyungan Kabupaten Bantul (Doctoral Dissertation, Universitas' Aisyiyah Yogyakarta)

Fuada, N. Muljati, S dan Hidayat, T.S. 2011 "Karakteristik Anak Balita Dengan Status Gizi Akut Dan Kronis Diperkotaan Dan Perdesaan, Di Indonesia" Jurnal Ekologi Kesehatan. 10 (3):174

Frojo, G. A., Rogers, N. G., Mazariegos, M., Keenan, J., \& Jolly, P. 2014. Relationship between the nutritional status of breastfeeding Mayan mothers and their infants in Guatemala. Maternal \& child nutrition, 10(2), 245-252.

Haileslassie, K., Mulugeta, A., \& Girma, M. 2013. Feeding practices, nutritional status and associated factors of lactating women in Samre Woreda, South Eastern Zone of Tigray, Ethiopia. Nutrition journal, 12(1), 28.

Kemenkes RI, 2013. Profil Kesehatan Indonesia. Jakarta: Kementrian Kesehatan Republik Indonesia

Kementerian Kesehatan, RI. (2014). Pedoman Gizi Seimbang. Jakarta. 
Lisa, C. Smith. Marie, T. Ruel, and Ndiaye, A. 2004 "Why Is Child Malnutrition Lower In Urban Than Rural Areas? Evidence From 36 Developing Countries" International Food Policy Research Institute FCNDP No. 176

Marimbi, H. 2010. Tumbuh Kembang, Status Gizi, Dan Imunisasi Dasar Pada Balita. Yogyakarta: Nuha Offset.

Mukhtadi, D. (2008). Strategi peningkatan kualitas sumberdaya manusia (SDM) untuk pencapaian MDGs-I. Departemen Ilmu Teknologi Pangan, Fakultas Teknologi Pangan - IPB. Bogor. Dalam Prosiding Focus Group Discussion. Kenaikan Harga BBM dan pencapaian MDG's:

Nuryani \& Rahmawati. 2018. Kebiasaan jajan berhubungan dengan status gizi sisa anak sekolah dikabupaten gorontalo. Jurnal gizi indonesia. 6(2).

Notoatmodjo S. (2003) Metode Penelitian Kesehatan. Jakarta : RINEKA Cipta

Porverawati, dkk. 2009. Gizi untuk Kebidanan. Yogyakarta: Nuha Medika.

Seafast. (2008). Prosiding Focus Group Discussion. Kenaikan harga BBM dan pencapaian MDG's: Eksplorasi opsi dari sudut pandang pangan, gizi dan kualitas sumberdaya manusia. SEAFAST Center. Bogor: IPB.

Seprianty,dkk. 2015. STATUS GIZI ANAK KELAS 3 SEKOLAH DASAR NEGERI 1 SUNGAILILIN. Jurnal kedokteran dan kesehatan, volume 2. No.1.

Soetjiningsih. 2009. Tumbuh Kembang Anak. Jakarta: EGC.

Sulistyani. 2010. Gizi Masyarakat 1. Jember. Jember Press University.

Supariasa, I. D. N., Bakri, B., Fajar, I. (2001). Penilaian Status Gizi. Jakarta: EGC.

Supariasa, I Dewa Nyoman, et al. 2002. Penilaian Status Gizi. Jakarta: EGC.

Wau Armen, 2018. Hubungan Pengetahuan, Sikap Dan Pernah Tidaknya Mengikuti Pelatihan Terhadap Keterampilan Kader Mengelola Posyandu Di Desa Sekip. Skripsi. 1-67.

WHO. 2002. Kader Kesehatan Masyarakat (The Community Health Worker). Jakarta : EGC 